\title{
Guest editorial: Pretending we do not know what everyone knows we know
}

\author{
Gavin Smith
}

Published online: 27 March 2011

(C) Springer Science+Business Media B.V. 2011

If editorials could start with epigraphs, mine for this one would be a comment by Zizek provoked by the Wikileaks "exposures": "The real disturbance was at the level of appearances: we can no longer pretend we don't know what everyone knows we know." (2011: 9) Here, I want to talk about professional intellectuals and their role in current politics, specifically about the agonies some anthropologists go through in trying to figure out what they should do or say in the public domain. Guided by Zizek - admittedly not a necessarily good thing for one's peace of mind - we might ask what is the kind of truth exposed by intellectual work when nobody out there can pretend they do not know what everyone knows they know.

The way I will do this is to take a particular instance of an anthropologist worrying about the role of the discipline in the current conjuncture (which she characterizes specifically, as, "global terror") and read this article pre-TELY, that is, prior to Tunisia, Egypt, Libya, Yemen [etc.]. But the winter events in the Mideast, combined with those in the Midwest, may help us to think about this thorny question of doing the work of a professional intellectual (in this case in the guise of an anthropologist) and relating that work to the sphere of public politics.

In the article, Werbner (2010) works through the dilemmas she faces as an ethnographer of Moslem people, some in Pakistan, some in the UK diaspora. She notes the willingness of some in other disciplines to leap on to the public stage and contrasts this with the way in which the complexity that an anthropologist such as herself recognizes, causes her-and perhaps us too-to hesitate to take on this public role. One of the many issues she raises is the fact that many Muslims, young or old, scholar, political figure, or community spokesperson have, perforce, been brought on to the public stage to become interpreters of their colleagues for the dominant media. Moreover, with each articulate and insightful intervention 
providing a slightly different perspective, what makes the sensitivity of the anthropologist to these complexities distinctively useful?

We are reminded of Gramsci's observation that the development of the masses and that of intellectuals is a dialectical process. People can do very effective anthropology without being trained in the guild. What perhaps has changed is that these people know they are doing this-providing interpretations of the collective groups to which they feel they belong. And in so knowing, they are made aware of their own positionality vis-a-vis what Gramsci would call the traditional intellectuals (much as we might grumble at such a designation). Professionals have a way of being quite patronizing about this, especially anthropologists in the historical constructivist school, who delight in showing us how "those people" have constructed a historical "narrative," and how this has happened-implicitly implying of course that there is something qualitatively different between those people's constructions and the constructions made by the interpretivist anthropologist. Something that Eric Wolf alluded to as, "the frisson effect."

So, given these parameters, we find the guild professionals forced to get out in the cold winds and state what precisely is the stuff of their profession-what claim do they have to a salary, a research grant or an audience for their monographs? And the changing nature of the institutions of scholarship adds a further note of desperation to these reflections.

It may appear that for anthropology, we all know that the discipline is inseparable from the study, through ethnographic fieldwork, of face-to-face interaction and practice hand, and the use of the notion, "culture," on the other. Readers may immediately distance themselves from these markers but, like it or not, this does seem to be the most broadly accepted understanding of what socio-cultural anthropologists do. Certainly, Werbner's entire exploration (perceptive though it is) relies on the former assumption, while the way in which applied anthropologists sell themselves to the military and are subjected to criticism for so doing, is based on a shared valuing of anthropological expertise in unraveling the mysteries of other people's "culture"specialized chroniclers "reporting back to the court that levied the funds for the voyage of discovery," as a recent reviewer so nicely put it. (Harding 2011: 17)

Indeed, a tension arises precisely because the latter claim, to be trained in the study and therefore, understanding of "culture" makes anthropologists feel that they should step onto the public stage in, for example, the intensified culture wars known as terrorism, while the small-scale exposure of their (albeit often long-term) fieldwork seems in some way to delegitimize what they can say about things that they have not themselves actually "seen" or "heard." The irony here is that precisely the discipline whose supposed method and conceptual instrument should bring it closest to "the people," is the one whose practitioners end up excusing themselves from the scene on the grounds of a kind of deeper intellectual insight; as though because they are closer to the people, so the standards they set for public intervention must be in some way higher than those in other disciplines. ${ }^{1}$

\footnotetext{
1 This of course leaves the field open not only to other disciplines but to anthropologists with less integrity. See for a recent example, Atran (2010) Talking to the enemy: violent extremism, sacred values and what it means to be human, a kind of applied anthropology which Jeremy Harding describes as, "what happens when a government pays experts whose research it ignores if they decide it's barking up
} 
The problem is that if one disagrees with the view that anthropology is about the study of small-scale phenomena and takes culture as either the object being studied or the quintessential tool of ethnography, then one can easily take refuge in a diametrically opposed position: that anthropology is not about small-scale interaction nor has very much to do with culture. As a result, the small-scale baby gets thrown out with the murky cultural bathwater. Instead, I would like to propose that while neither culture nor scale need be of indifference to one anthropologist or another if they so prefer, anthropology is importantly about other things as well, other things which, if left unexamined, limit the critical edge-even of a cultural ethnography of the small scale.

The kind of anthropology I am referring is about the exposure for critical examination of the clashing of connections that arise crucially at moments of historical and spatial conjuncture; indeed, since I do not mean either/or but both simultaneously perhaps, it would be better to refer to spatio-temporal conjuncture. The problem is first that the scale for this kind of enquiry cannot be pre-determined and certainly not by some fetish of "being-there" fieldwork; and second, while such conjunctures may find expression or be experienced along a cultural plain (however one wishes to understand that term), this is not the level at which these fields of force come into tension. I don't mean then the kind of exposure that comes with interpretative techniques directed at truculent cultural phenomena. Rather, I mean first acknowledging that there are important elements of historical process that are not immediately available to practical sense and therefore require exposure through techniques of defamiliarization quite different from those of cultural theory. This attentive problematizing of concrete abstractions should be as much as part of our work as participant observation and cultural interpretation, and yet it is largely absent in recent anthropological literature. ${ }^{2}$

At the fear of being misread here, let me insist that I am not arguing for the denegration of what have become the almost taken for granted features of anthropological enquiry. I am simply proposing that in our rush to occupy that ground-perhaps as the experts (in deep ethnography and cultural interpretation) many of us fail to turn the hermeneutics of suspicion on the spatio-temporal conjuncture that arises in a field infinitely broader than that of any kind of fieldwork. Moreover, while this may once have been the result simply of practical issues of research time and limitations of competence, current myopia is authorized precisely by what ethnography and cultural anthropology have come to mean.

In the remainder of the space I have here, I will try to illustrate just this one element of what in effect should be a multiple critical engagement with reality (Comaroff 2010) - and I will now do this post-TELY. What seems striking about

\footnotetext{
Footnote 1 continued

the wrong tree" Harding (2011: 17). Harding then asks, "Is this really anthropology? Or is it some zombie discipline that needs to feed on flesh from other disciplines..." (ibid 18).

2 Though not of course in older literature such as that of Steward, Wolf and Mintz to name just a few. Levi-Strauss's discussion in Tristes Tropiques of the geological metaphor of 'layers' which he associates with Marx's method is also an instance of what I am talking about here.
} 
Werbner's exploration of the dilemmas she faces as an anthropologist is the way in which her assumptions about what anthropology is, compartmentalize the formulation of her problematic from the broader historical context in which her enquiry is taking place-what I am calling here the spatio-temporal conjuncture. It is quite striking how little the constitution of something called, "Global Terror," is not itself defamiliarized. It is simply there; something that creates a set of dilemmas for the ethnographer. But, insofar as conjunctures are always a result of overdetermined connections, so what has been called the post-traumatic stress disorder following 9/11 (i.e., the War on Terror) needs also to be thought in relation to the stresses and strains of capitalism, states and super states as the tectonic plates of reproductive circuits grind against one another. (See for example, the way Arrighi 2007; Friedman 2011; and Kalb and Tak 2005 configure these processes.) The current state of these fields of force are not in an entirely different compartment from what is taken for granted-dare I say, at the level of culture-as the basis of a healthy economy and the proper working of democracy which, taken together, are supposed to ensure (most of) our well-being, in contradistinction to those in whose lives these two elements are deficient or entirely absent. Put bluntly, the War on Terror is directed against elusive figures whose primary threat is their potential for bringing the economy to a standstill and their refusal to believe in what is usually called "the values of liberal democracy".

I am writing this piece in a hotel room in New York City. It is February and what are frequently referred to as "revolutions" are taking place in the Mideast, while in the Midwest people are in the streets too, though here it is public service unions facing off against Republican legislatures. On the table beside me are copies of the New York Times and the London Review of Books. In the Times, the White House communications director speaks of false claims that the White House is in any way involved in "the grass-roots opposition that is happening in Wisconsin" (Calmes 2011: A11). My liberal democratic values lead me to ask myself what would be wrong with a democratically elected president actually wanting to be associated with a grass-roots movement for workers rights? I am assured time and again in every newspaper I pick up (a) that this is what the "revolutions" in the Mideast are about; and (b) that it would be optimistic (sic) for us (sic) to expect that what will happen in the course of these revolutions is that people will get, or even want, "liberal democratic values." Then I pick up the London Review and read, "even as Obama increased pressure on Mubarek to stand down, he refused to side with the demonstrators, [and] reserved his highest praise for the military" (Shatz 2011: 7).

So there seems to be something of a kink in at least one element of what makes for a society of well-being, let us call it an inflation of "value" in what liberal democracy actually is. What about the other element, a healthy economy? Well it is not hard to see how this is playing out in the Midwest. One segment of the population associate the well-being they might derive from a healthy economy with the right to collective bargaining. Another segment of the population, a rather small segment in fact, just two of them (blessed with the name Koch), is of the view that collective rights get in the way of a healthy economy, this latter being about profits. And the political part of this particular economy is that while the larger segments rely for their well-being on wages, the smaller segments, owners of the 
second-largest privately held company in the USA, have increasingly been shifting the source of their profits from resource extraction and refining into speculation and finance. This is a form of capital which, as I have noted elsewhere (Smith 2011), is about the capture (or enclosure), rather than the production, of value-i.e., what David Harvey calls, "a class concentrating" project. What makes this especially "political" is that one segment of the population relates to the institution of actually existing liberal democracy through voice, the other does so by channeling vast amounts of cash into the coffers of a political party.

The "revolutions" in the Mideast on the other hand cannot be understood in these terms. The only possible connection might be that Koch Industries is second only to Cargill in the rankings of private capital and Cargill is, among its many operations, the major agricultural commodity trader in the world. So if conjunctures are about connections, here are some: in Sept 2010 Russia, one of the world's biggest exporters of wheat, suffered a drop of $31 \%$ in output; by mid-month Medvedev had banned all exports. As they say, you do not have to be a rocket scientist if you are in the futures business at this point. Wheat futures went from 440 cents a bushel in July to over 800 cents in December. So here is question number one: which country is the world's largest wheat importer? Answer: Egypt. In September, the BBC was reporting "Ukraine, another huge grain exporter, was considering a ban, forcing several large customers, including Egypt to search for alternative supplies" (BBC 10 Sept 10 2010). By the time of the "Facebook Revolution," the wholesale cost of food hit its highest monthly figure on record, according to the FAO (BBC 3 Feb 11 2011).

So the multitude was hungry. Remember what Hardt and Negri have told us: there is no longer a class enemy for the multitude, so this is a far cry from the whitecollar unions facing off against the likes of the Kochs in the Midwest. Except that Egypt has long had the most unionized labor force in the Arab world and, thanks to structural adjustment, which put in place the apparatus that concentrated capital (especially public resources) in the hands of national cliques best positioned to engineer this capture, there was a pretty undisguised capitalist class too. We had already seen how this worked in Tunisia for the Abidine Ben Ali clan, the president's wife's plane scarcely able to take off for Saudi Arabia for the weight of the gold it was carrying.

This brings us to question number two. Who is the second biggest importer of US military aid (next only to Israel)? Egypt, of course. This, combined with the greased wheels of structural adjustment, meant that "Egypt's military is an economic conglomerate with retired generals running companies that manufacture cars, appliances and several other products, all with enormous tax breaks" (Martin 2011). This is not to say that what is happening in Egypt is just a variation of something happening in Wisconsin. Though it may mean that Obama's squeamishness in supporting grass-roots democracy in both places is not a million miles removed from what is seen to be the basis for a healthy economy in each case. And observations of this kind do, in my view, make a good case for exposing not just any linkages of obscured connection but especially those of political economy per se.

I do not point up linkages such as these in the belief that the exercise constitutes a comprehensive or even adequate exposure of a spatio-temporal conjuncture. Rather 
my purpose has been simply to illustrate that some of these kinds of things matternot in the sense that they are, "context" or "setting," for what otherwise will be the more critically acute component: cultural ethnography. Instead, I am arguing that the features of the spatio-temporal conjuncture are integral to what can be understood about the cultural ethnography. Critical engagement by the anthropologist with this dimension of the real world is therefore essential not just in general and once and for all, but in each and every instance of research engagement.

So we return to Zizek post-Wikileaks, "we can no longer pretend we don't know what everyone knows we know" (2011: 9). Applied to anthropologists, I think this suggests that confining the insights of critique to localized ethnography and a level of reality captured in the notion, "culture," does not constitute responsible scholarship. The kind of critical awareness that drives our methods in these spheres of the social world needs to be extended to a sustained exposure of the underlying connections that produce the spatio-temporal conjuncture in which our work takes place: "what everyone knows we know...". All of the material presented in the latter part of this editorial comes from sources we all read in our daily lives; it is what we know we know. If we do not subject it to the acid test we reserve for the other foci of our work, we run the risk of a kind of scholastic siege mentality, chattering among ourselves about the niceties of our latest insights into the intimacies of ethnography and the mysteries of culture, while nervously fidgeting about the relevance of our work for anybody else.

\section{References}

Arrighi, Giovanni. 2007. Adam Smith in Beijing: Lineages of the twenty-first century. London: Verso.

Atran, Scott. 2010. Talking to the enemy: Violent extremism, sacred values and what it means to be human. London: Allen Lane.

BBC News Website. 2010. "US cuts wheat production forecast" 10 Sept 10.

BBC News Website. 2011. "Why food prices and fuel costs are going up" 3 Feb 11.

Calmes, Jackie. 2011. "Wisconsin battle puts president between competing political desires". New York Times [National] Feb 21. A11.

Comaroff, John. 2010. The end of anthropology, again: On the future of an in/discipline. American Anthropologist 12 (4): 524-538.

Friedman, 2011 [Forthcoming]. Putting globalization in its place. In Class and anthropology, ed. Carrier and Kalb. Oxford: Berghahn.

Harding, Jeremy. 2011. "Where the Jihadis are". London Review of Books 33 (4): 17-19. 17 Feb.

Kalb D. and H. Tak, eds. 2005. Critical junctions-recapturing Anthropology and history. In Critical junctions: Anthropology and history beyond the cultural turn. Oxford: Berghahn.

Martin, P. 2011. "How will Arab Spring reshape the Mideast?" Globe and Mail: A6. 26 Feb.

Shatz, Adam. 2011. After Mubarak. London Review of Books 33 (4): 7-8.

Smith, Gavin. 2011. Selective hegemony and beyond, populations with 'no productive function': A framework for enquiry. Identities: Global Studies in Culture and Power 18 (4) [Forthcoming].

Werbner, Pnina. 2010. Notes from a small place: Anthropological blues in the face of global terror. Current Anthropology 51 (2): 193-206.

Zizek, Slavoj. 2011. "Good manners in the age of Wikileaks". London Review of Books 33 (2). 20 Jan. 